\title{
Inhaltsverzeichnis/Contents
}
H. Weber,
D. Metzger,
R. Dekumbis
G. W. Ehrenstein, V. Altstädt

B. Bauer,

B. Egg

\section{J.-L. Chermant, M. Coster}
A. V. Reddy, D. P. Lahiri

Abnützungserscheinungen an metallographischen Poliertüchern

Signs of Wear in Metallographic Polishing Cloths 431

Präparationsmethoden zur Darstellung des strukturellen Aufbaus glasfaserverstärkter Thermoplaste

Methods of Preparation to Reveal the Structural Arrangements of Glass Fibre Reinforced Thermoplastics

Ein optimierter Rückstreuelektronendetektor für das Rasterelektronenmikroskop

An Optimised Back Scattered Electron Detector for the Scanning Electron Microscope 460

Application of Quantitative Metallography to Sintering Investigations

Part 3: Instrumentation, Technics and Representativity of Measurements in Quantitative Image Analysis

Anwendung der quantitativen Metallographie auf die Untersuchung von Sintervorgängen

Teil 3: Geräte, Verfahren und Repräsentativität der Messungen bei der quantitativen Bildanalyse 472

Failure of Aeroengine Centre Support Bearing Schaden an einem Achslager eines Flugzeugs $\quad 485$

Tagungskalender/Meeting Diary 


\section{Refohert lung}

\section{Information 51}

\section{Metallmikroskope \\ der neuen Generation}

für Materialkontrolle und Forschung

$\mathrm{MeF} 3$

Weitfeld-Auflichtmikroskop

in umgekehrter Bauart

Modulsystem zum raschen Wechsel älternativer Mikroskopiermethoden:

- Hellfeld

- Dunkelfeld

- Polarisation

- Fluoreszenz

- Interferenzkontrast

- Polarisationskontrast

- Interferometrie
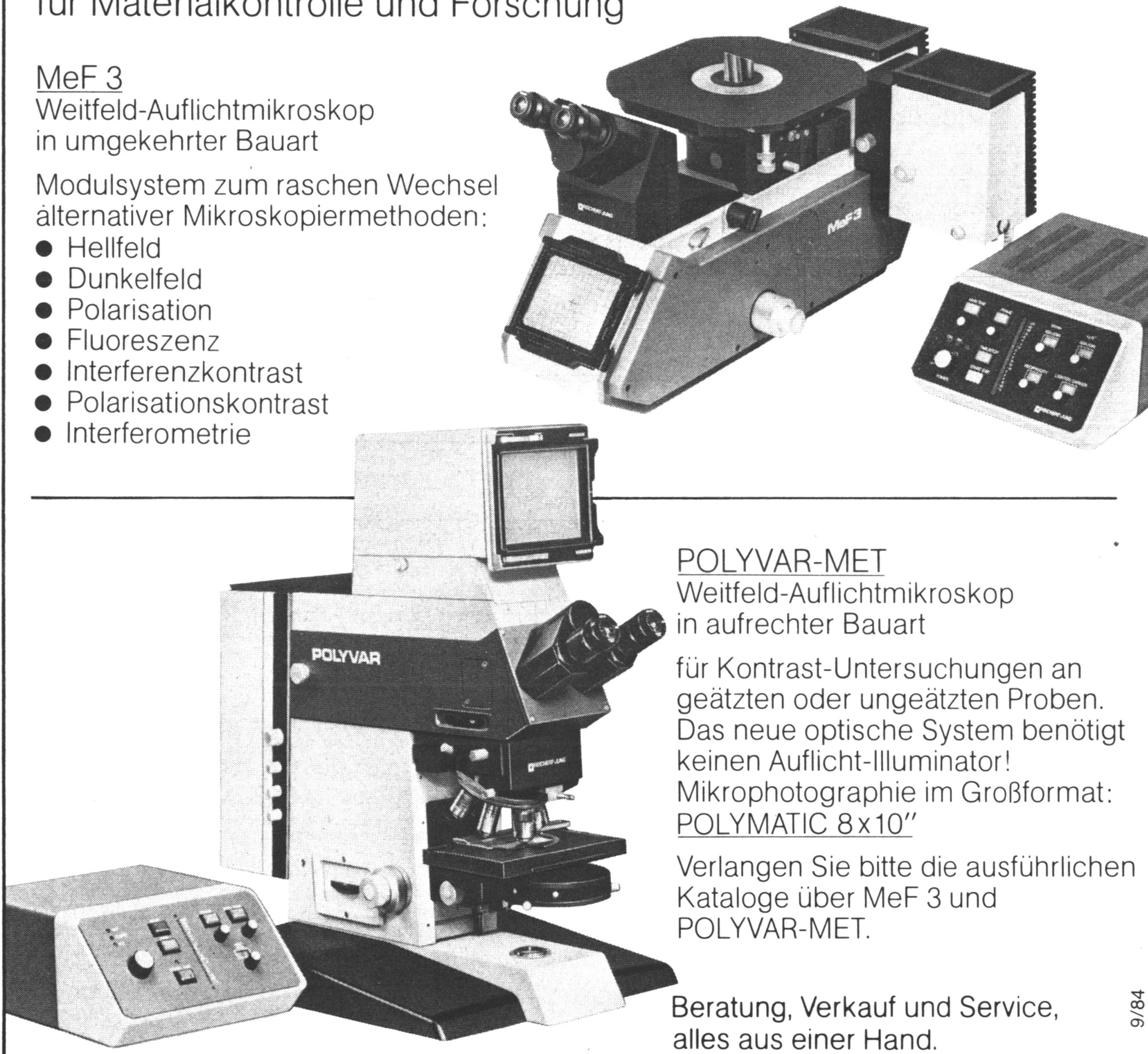

POLYVAR-MET

Weitfeld-Auflichtmikroskop in aufrechter Bauart

für Kontrast-Untersuchungen an geätzten oder ungeätzten Proben. Das neue optische System benötigt keinen Auflicht-Illuminator! Mikrophotographie im Großformat: POLYMATIC $8 \times 10^{\prime \prime}$

Verlangen Sie bitte die ausführlichen Kataloge über MeF 3 und POLYVAR-MET.

Beratung, Verkauf und Service, alles aus einer Hand.

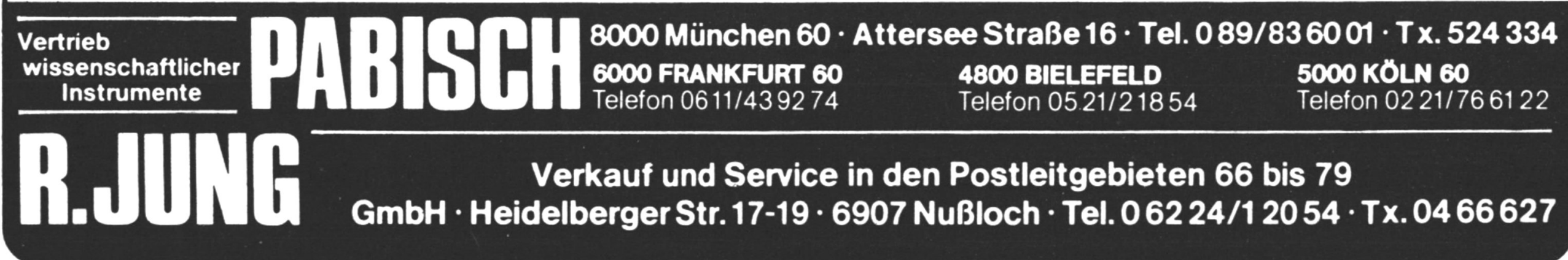

